\title{
The effect of compression ratio on exhaust emissions from a PCCI Diesel engine
}

\author{
O. Laguitton, C. Crua, T. Cowell, M.R. Heikal, M.R. Gold \\ Internal Combustion Engine Group, School of Engineering, University of Brighton, Brighton BN2 4GJ, UK
}

Published in: Combustion and Flame (http://www.elsevier.com/locate/inca/269)

Received 5 Dec 2006; received in revised form 14 May 2006; accepted 15 May 2006

\section{Citation:}

O. Laguitton, C. Crua, T. Cowell, M.R. Heikal, M.R. Gold, (2007) "The effect of compression ratio on exhaust emissions from a PCCI diesel engine", Energy Conversion \& Management (in press)

\section{Corresponding author:}

Dr. Cyril Crua

Internal Combustion Engine Group

School of Engineering

Cockcroft Building

University of Brighton

Lewes Road

Brighton BN2 4GJ

Tel: $\quad$ +44 (0)1273642312

Fax: $\quad$ +44 (0)1273642444

E-mail: c.crua@brighton.ac.uk 


\begin{abstract}
A description of the development of a single cylinder test facility is presented, being based on a production 4-cylinder DI Diesel engine and designed to allow study of the emissions characteristics over a very wide range of operating conditions. The objective was to establish how engine out $\mathrm{NO}_{\mathrm{x}}$ emissions can be reduced to the estimated levels required by the next emissions target 'Euro 6' and thus be able to apply the findings to the original 4-cylinder engine and minimise the requirement for currently immature NOx after treatment. It has been proposed that further reduction in compression ratio beyond current levels would be beneficial to engine out emissions and specific power, and could be facilitated by developments in cold start technology. The results of a study using this single cylinder facility to evaluate the effect of reducing compression ratio from 18.4 to 16.0 are presented. It was found that, although there was a small $\mathrm{CO}$ and $\mathrm{HC}$ penalty, either reducing the compression ratio or retarding the injection timing greatly reduced NOx and soot emissions when both premixed and diffusion-combustion phases were present. This effect was less significant when the combustion was solely premixed.
\end{abstract}

Keywords: Diesel emissions; Diesel combustion strategies; Compression ratio

\title{
1. Introduction
}

One of the most critical challenges ahead for the Diesel passenger-car engine is to meet future emissions regulations whilst improving performance and fuel economy with a minimal cost penalty. The current and emerging after-treatment technologies give encouraging results, but their cost and complexity threaten the competitiveness of the Diesel engine package. Conversely, over the past decade, research in Diesel homogeneous charge combustion has highlighted an alternative approach for significant engine out reductions of nitrogen oxides (NOx) and Particulate Matter (PM) emissions [1-9]. Importantly, it demonstrates the capability of simultaneously reducing NOx and PM emissions, thus potentially offering an extended use of Diesel engines without, or with greatly reduced, after-treatment requirements. There are two possible approaches to achieve this ultra-low emissions combustion, where both aim to obtain a lean and highly mixed charge prior to combustion.

The first is HCCI (Homogeneous Charge Compression Ignition), relying on early injections to achieve a chemically and physically homogeneous mixture before autoignition. Homogeneous charge combustion is closer to the ideal constant-volume Otto cycle, as observed in Ref. [6]. There is no diffusion flame but a global nearinstantaneous combustion, offering the same ultra-low NOx and soot emissions characteristics as HCCI for the gasoline application. The locally lean nature of the mixture results in negligible soot emissions and ultra-low NOx emissions due to the low flame temperatures. Typically, two distinct stages are present in the combustion with HCCI operation, the first stage is associated with the initial rupture of the long carbon chains, often referred to as cool combustion or low temperature oxidation [10]. This initiates the active radicals, which trigger the main combustion, also referred to as the high temperature oxidation. For high AFRs (Air-Fuel Ratios), the cool combustion results in an increase in in-cylinder temperature until the main combustion is triggered (the second distinct peak of the heat release). EGR (Exhaust Gas Recirculation) is used 
to reduce the oxygen concentration and to control the rate of combustion by acting as a heat sink, especially for the higher loads where closer-to-stoichiometric mixtures are present.

The second approach to ultra-low emissions is PCCI (Premixed Charge Compression Ignition), which relies on late injections and high EGR rates to delay the auto-ignition. Compared to HCCI, PCCI offers lower NOx and soot reductions, but it does not exhibit the higher $\mathrm{HC}, \mathrm{CO}$, noise emissions, and the very tight requirements for homogeneity and leanness. PCCI is a single-stage combustion process closer to the premixed phase of conventional Diesel combustion, than the low and high temperature oxidations seen with HCCI [11]. PCCI is an approach generally more adapted to Diesel-fuelled applications as it does not rely on early injection timings when the piston is low in the cylinder and is therefore less prone to wall wetting with the inevitable high increases in $\mathrm{HC}$ and $\mathrm{CO}$ emissions. Furthermore, the combustion is not fully decoupled from the injection as in HCCI operation due to the late injections, allowing for greater control over the start of combustion.

The programme of work described here presents an exploration of the fundamentals of PCCI Diesel combustion to achieve low engine-out emissions, in particular the impact of reduced compression ratio on NOx and soot emissions.

\section{Experimental Approach}

\subsection{Apparatus}

In order to allow as wide an exploration as possible, a single-cylinder Diesel research engine was used with a configuration based on that of a current production 2.0 litre, four cylinder automotive engine. Two engine builds were available: Build \#1 was a singlecylinder version of the four cylinder engine, and was used to define a baseline derived from existing multi-cylinder engine test data; Build \#2 was the configuration to be used through the advanced combustion investigations. Details are shown in Table 1. The test cell was developed to offer independent control of inlet-air pressure and temperature, exhaust backpressure, EGR temperature, and injection pressure, opening the envelope beyond any hardware limiting characteristics such as those of an engine mounted high pressure fuel pump or turbocharger.

A flush-mounted in-cylinder pressure transducer was selected for its ability to provide accurate high speed transient pressure data, suitable for heat release calculations, which were considered as the key characteristics for the analysis of the combustion. Both oil and coolant engine-in temperatures were set at $90^{\circ} \mathrm{C}$ with flows maintained constant. The exhaust and EGR systems were particularly complex since they had the difficult task of replicating the 4-cylinder engine systems by providing the same functionalities and gas handling dynamic characteristics while being fed by a single cylinder. Beyond its primary role, the exhaust system was designed to provide a stable exhaust gas supply for EGR. In an effort to reduce the effect of pulsating gas flows, an exhaust chamber was inserted upstream from the EGR supply point. Although the overall size of the EGR circuit has been increased on the single-cylinder engine (over the production engine), the addition of two heat exchangers, a bypass, two temperature control valves and a rate valve have the advantage of providing a level of functionality rare in engine test facilities. The emissions analysis system comprised of an AVL 415 Variable Sampling Smoke Meter and a HORIBA MEXA 7100DEGR exhaust gas analyser. In addition an AVL 733 Dynamic Fuel Meter was used. The fuel 
used throughout the investigations was Diesel BP FORD reference fuel with ultra-low sulphur Diesel fuel with a cetane number of 53.5 , a density of $835 \mathrm{~kg} / \mathrm{m} 3$ and a gross calorific value of $46 \mathrm{MJ} / \mathrm{kg}$. The test cell and data acquisition were managed using a custom-built controller, while an EMTRONIX controller was used for the injectionsystem with high-speed data acquired using an MTS CAS system. Emissions data were collected and averaged over 30s while 100 cycles of high-speed data were collected.

\subsection{Approach}

The investigations focused on matching emissions and fuel consumption and the incylinder pressure profile during the engine cycle as well as derived parameters such as the rate of pressure change. Both qualitative and quantitative information were used to explain the various effects observed on the combustion during the investigations. Qualitative assessments were made of the shape of the pressure profile during the initial part of the combustion, the portion of the premixed combustion, defined by a peak shape, and diffusion combustion, defined by a lower rate of pressure change. The quantitative data, derived from the mean cylinder pressure traces, were the start and end of combustion, the maximum rate of pressure change and the phasing of the heat release or pressure change relative to TDC. Early in the course of the investigation, it was found that single-cycle profiles of rates of pressure change offered the most representative data due to the characteristics defined by the PCCI combustion. This was due to the fact that, despite an apparent combustion stability there was a temporal cycleto-cycle variation where ensemble averaging could lead to a smoothed, unrepresentative profile, with longer duration and lower rates as depicted in Figure 1. As a consequence, before the analysis could progress, a single, representative engine cycle was selected for each test point from the 100 engine cycles. The selection was based on it offering a good representation of the combustion, in terms of start of combustion and angle of 50 $\%$ burn. In the illustration shown in Figure 1, the selection of the pressure trace 2 would have been made.

\section{Effect of compression ratio}

The aim of the reduced compression ratio is to reduce the in-cylinder temperatures, hence flame temperatures during the combustion to suppress NOx emissions. Major reductions have not been implemented to date due to the associated negative effect on cold-start capability. In view of the developments in cold-start technology and with the appearance of variable compression ratio technology, this route now appears to be a feasible option for future engines. In order to exploit these possibilities, modifications were made to the piston to reduce the compression ratio from 18.4 to $16.0: 1$ in the Build \#2 engine. The compression ratio reduction was achieved by reducing the bowl pip size (Figure 2), while maintaining a production engine squish height, which directly influences mixing and injector targeting.

The main objective for these investigations was to understand the impact of compression ratio on the fuel-air mixing and combustion characteristics at part load. Three key operating points were defined KP1, $1500 \mathrm{rev} / \mathrm{min} 3.0$ bar GIMEP, KP2 2000 rev/min 7.7 bar GIMEP and KP3 $2000 \mathrm{rev} / \mathrm{min}$ and 10.8 bar GIMEP. They were chosen to be representative of light to high load conditions, which predominate in the European drive cycle. Injection-timing responses conducted on the Build \#1 engine were repeated on the Build \#2 engine with particular attention given to match Build \#2 engine 
operating conditions, performance and emissions with those of Build \#1, as can be seen in Table 2.

Since it was likely that there would be slight discrepancies between the multi and single cylinder engines, the aim was only to adjust the main-injection quantity to achieve the gross load (GIMEP), as this approach constituted an accurate measurement on a singlecylinder engine and enabled the investigations to focus on the compression and expansion strokes, avoiding complications with the differences in pumping and friction losses. Although the intention had been to match the injection strategy between builds it was found necessary to modify the pilot injection slightly at the lower compression ratio to achieve satisfactory combustion. The main characteristics analysed are indicated on Figure 3.

Figure 4 shows the impact of compression ratio on NOx emissions recorded at the three loads tested. NOx emissions decreased as the injection timing was retarded, and were also lowered when the compression ratio was reduced from 18.4:1 to 16.0:1. The reductions were more pronounced at the higher loads KP2 and KP3. At the light load $\mathrm{KP} 1$, only small benefits from the lower compression ratio were observed, likely to be linked with the already limited high-temperature, stoichiometric combustion. As the injection timing was retarded, the emissions differences between engine builds became negligibly small, which would suggest that the influence of in-cylinder pressure and temperature was reduced below a threshold, as was already the case at KP1. This highlights that NOx emissions under premixed combustion were mainly controlled by other operating conditions such as AFR and EGR rate, rather than temperature and pressure.

The effects of a reduced compression ratio on the in-cylinder pressure and temperature reached at auto-ignition are shown in Figure 5, as a function of the injection timing. The maximum temperatures reached before the combustion were lower for a compression ratio of 16:1, as calculated using the perfect gas law and polytropic coefficients derived from high-speed pressure data. The temperatures dropped from $260^{\circ} \mathrm{C}$ to $230^{\circ} \mathrm{C}$ at $\mathrm{KP} 1$ and from $175^{\circ} \mathrm{C}$ to $150^{\circ} \mathrm{C}$ at $\mathrm{KP} 3$ in Build $\# 2$ engine. This did not represent a large reduction relative to the peak flame temperatures but would act in two ways. Firstly, it would delay the auto-ignition hence increase the mixing time, which further reduces the starting temperature for the combustion along the expansion stroke. Secondly, the rate of combustion would reduce, as the fuel-air mixing would reduce the portion of stoichiometric fuel-air mixture. The lower pressures during the injection event would enhance fuel-air mixing by enabling the fuel spray to penetrate further and entrain more air. This increased mixing is also expected to delay autoignition and assist the mixture to lean out.

The fact that NOx emissions converged at the most retarded injection timings in Figure 4, but that the in-cylinder pressures and temperatures did not, emphasises that NOx emissions were not solely dependent on pressure or temperature. This contradicts the generally accepted strong link between temperatures at the start of combustion and NOx emissions. At the light load KP1, an examination of the rates of pressure change showed that the combustion profile resembled a fully-premixed charge combustion for both engine builds and across all injection timings. This led to very similar NOx emissions in both cases, which were therefore less sensitive to in-cylinder pressure or temperature. However, an observation of the rates of pressure change at KP2 and KP3 revealed a change in the combustion type during the injection-timing response. It progressed from combined premixed and diffusion combustion at the most advanced 
injection timings to largely premixed-charge combustions at the more retarded injection timings. The fact that NOx emissions converged as diffusion combustion reduced consolidated the conclusions of Heywood [12] that NOx emissions formed during diffusion combustion of a close-to-stoichiometric mixture are very sensitive to incylinder pressures and temperatures. These results imply that NOx emissions formed during premixed combustion are less affected by in-cylinder pressure or temperature and highlight the existence of the third factor, the combination of AFR and EGR rate or local oxygen concentration, which seems to become dominant below a certain temperature threshold or during fully-premixed-charge combustion events.

As can be seen in Figure 6, the lower in-cylinder pressures and temperatures, as well as the increased mixing contributed to delay in auto-ignition. For comparable injection timings, the start of combustion was generally delayed by 2 to $4^{\circ} \mathrm{CA}$. These increased auto-ignition delays were in line with optical spray-rig observations made in Ref. [13]. The increased delay which resulted in longer mixing times gives rise to larger premixed-combustion phases and conversely less diffusion combustion. The impact of the lower pressure and increased auto-ignition delay are cumulative, since the delay also allowed more time for the fuel to penetrate still further. At the light load KP1, where there was fully-premixed-charge combustion, the slower rate of combustion of the same amount of fuel due to the lower compression ratio or retarded injection timing also led to a lower maximum rate of pressure change, as can be seen in Figure 7. However, in the case of combined premixed and diffusion combustion, typical at higher loads, it is believed that an increased portion of premixed-fuel burning simultaneously compensated for the slower rate of combustion, which can be seen in the maximum rates of pressure change. This would be consistent with the high noise levels recorded with HCCI.

Both high noise and NOx emissions are usually associated with high rates of pressure change, since these are a result of a rapid rate of combustion during premixedcombustion. This consequently leads to a high increase in the in-cylinder temperature, and hence a faster rate of combustion during the diffusion-combustion phase, thereby leading to a greater proportion of NOx forming conditions. However, it is thought that engine noise with a highly, but not fully, premixed-charge combustion should not be considered as an indication of NOx emissions but as an indication of rapid and predominantly premixed-combustion. A comment can be made concerning the variation with injection timing at each key point. KP1 results are expected to be the most accurate since they were obtained for fully-premixed-charge combustion which is characterised by a smooth pressure change profile. However, obtaining a maximum rate of pressure change during combustion events with both premixed and diffusion combustion presented difficulties, in processing and hence in drawing conclusions.

Although not as pronounced as for engine out NOx emissions, reducing the compression did lead to lower soot emissions within the measurement accuracy of the smoke meter. The main effect was seen at the light load KP1 where smoke emissions were almost halved in Build \#2 engine compared with Build \#1 engine (Figure 8). It is believed that PM was formed during the combustion in Build \#1 engine but that incylinder temperatures were too low to promote its post-combustion oxidation. In the case of Build \#2 engine, it is believed that the increased mixing associated with the lower compression ratio suppressed PM formation, eliminating the need for high incylinder temperatures for the oxidation process.

The compression ratio did not seem to affect fuel consumption very much, as seen in 
Figure 9, which shows the fuel consumption during injection-timing responses at the three loads tested in both engine builds. The difference between engine builds was close to the measurement accuracy of $+/-1.0 \%$ and may therefore be considered negligible except at key point 3 , where a clear increase in fuel consumption is seen. Since the tests were carried out at fixed gross indicated load, the fuel consumption was a measure of the fuel conversion efficiency and concealed any differences in friction.

The impact of the change of compression ratio on $\mathrm{HC}$ emissions was largest at the lowest load condition KP1. It is believed that the conditions for $\mathrm{HC}$ formation are more prevalent at light loads with lower in-cylinder pressures and temperatures leading to over-leaning and quenching of the flame and thus to $\mathrm{HC}$ emissions. The increase of $\mathrm{HC}$ emissions follows a similar reasoning as for PM, where the lower compression ratio engine offers a reduced pressure at the start of injection and a longer penetration time due to the increased auto-ignition delay and subsequent increased penetration of the fuel spray into the chamber. This leads to excessive fuel-air dilution from increased mixing at the boundary of the mixture. In addition, the increased penetration of the fuel spray is more likely to reach the colder cylinder walls or piston bowl, as in gasoline applications, which provides ideal conditions for flame quenching, incomplete combustion and pool fires. It was found that $\mathrm{CO}$ emissions varied similarly to $\mathrm{HC}$ emissions.

\section{Conclusions}

The work described has shown how compression ratio and injection timing assist in achieving lower NOx and soot emissions over a broader operating region. This approach has aimed to achieve HCCI operation levels of engine out NOx and soot emissions whilst minimising $\mathrm{HC}$ and $\mathrm{CO}$ emissions. The exploration of the fundamentals of Diesel combustion to achieve low engine-out emissions has resulted in an improved understanding of the in-cylinder phenomena and the relationship with emissions formation.

In order to allow an extensive exploration, a single-cylinder Diesel engine was employed and the test cell was designed such that operating conditions could be set independently precluding the limitation imposed by multi-cylinder production hardware characteristics.

The impact of reducing compression ratio has been assessed across three part load conditions. In each case, as injection timing was varied, fuelling was adjusted to maintain constant GIMEP. With the low compression build at part load, soot and NOx emissions were reduced with the latter effect diminishing as injection timing was retarded. It was concluded that lower pressure and temperature during the injection and combustion promoted fuel-air mixing, which reduced both the rate of combustion and proportion of diffusion combustion. When diffusion combustion was suppressed, the results showed NOx emissions to be less sensitive to in-cylinder pressure and temperature. It was found that when the starting point was a fully-premixed-charge combustion, reducing the compression ratio decreased the maximum rate of pressure change, whereas when diffusion combustion was present, its reduction fuelled the premixed combustion thereby increasing the maximum rate of pressure change. These investigations have illustrated that reducing compression ratio offers similar benefits to those of retarded injection timing, but that noise emissions are increased with combined premixed and diffusion combustion. 


\section{Acknowledgements}

The authors wish to acknowledge the support received by the "Royal Commission for the Exhibition of 1851" through the Industrial Fellowship scheme.

\section{References}

[1] Takeda Y, Keiichi Na, Keiichi, Ni. Emission characteristics of premixed lean Diesel combustion with extremely early staged fuel injection. SAE 961163; 1996.

[2] Aoyama T, Hattori Y, Mizuta J, Sato Y. An experimental study on premixed-charge compression ignition gasoline engine. SAE 960081; 1996.

[3] Yanagihara H, Sato Y, Mizuta J. A study of DI Diesel combustion under uniform higher-dispersed mixture formation. JSAE Review July 1997;247-54.

[4] Suzuki H, Koike N, Ishii H, Odaka M. Exhaust purification of Diesel engines by homogeneous charge with compression ignition Part 1: Experimental investigation of combustion and exhaust emission behavior under pre-mixed homogeneous charge compression ignition method. SAE 970313; 1997.

[5] Yokota H, Kudo Y, Nakajima H, Kakegawa T, Suzuki T. A new concept for low emission Diesel combustion. SAE 970891; 1997.

[6] Beatrice C, Bertoli C, Migliaccio M. Basic concepts of the homogeneous charge compression ignition engines. ATA 2002; 55(7/8):226-34.

[7] Kawashima J-I, Ogawa H, Tsuru Y. Research on a variable swirl intake port for 4valve high-speed DI Diesel engines. SAE 982680; 1998.

[8] Iwabuchi Y, Kawai K, Shoji T, Takeda Y. Trial of new concept Diesel combustion system - Premixed compression-ignited combustion. SAE 1999-01-0185; 1999.

[9] Gatellier B, Walter B. Development of the high power NADITM concept using dual mode Diesel combustion to achieve zero NOx and particulate emissions. Thiesel 2002; 131-43 and SAE 2002-01-1744; 2002.

[10] Simescu S, Fiveland SB, Dodge LG. An experimental investigation of PCCI-DI combustion and emissions in a heavy-duty Diesel engine. SAE 2003-01-0345; 2003. [11] Kimura S, Aoki O, Ogawa H, Muranaka S, Enomoto Y. New combustion concept for ultra-clean and high-efficiency small DI Diesel engines. SAE 1999-01-3681; 1999. [12] Heywood JB. Internal combustion engine fundamentals. McGraw-Hill; 1988, p. 567-648

[13] Crua C. Combustion processes in a Diesel engine, Thesis ( $\mathrm{PhD})$, University of Brighton, UK; 2002. www.crua.net/thesis 


\section{Captions}

Figure 1: Effect of ensemble averaging on combustion characteristics.

Figure 2: Piston-bowl cross-sections for builds \#1 and \#2 (added volume for build \#2 is shown in black).

Figure 3: Illustration of the in-cylinder and combustion characteristics analysed.

Figure 4: Impact of compression ratio on NOx emissions.

Figure 5: Impact of compression ratio on in-cylinder pressure and temperature at autoignition.

Figure 6: Impact of compression ratio on auto-ignition delay.

Figure 7: Impact of compression ratio on maximum rate of pressure change.

Figure 8: Impact of compression ratio on smoke emissions.

Figure 9: Impact of compression ratio on fuel consumption.

Table 1: Summary of specifications for Build \#1 and Build \#2 engines.

Table 2: Main operating conditions and hardware values or ranges investigated. 


\section{Figures}

Figure 1

\section{Conventional diesel combustion}

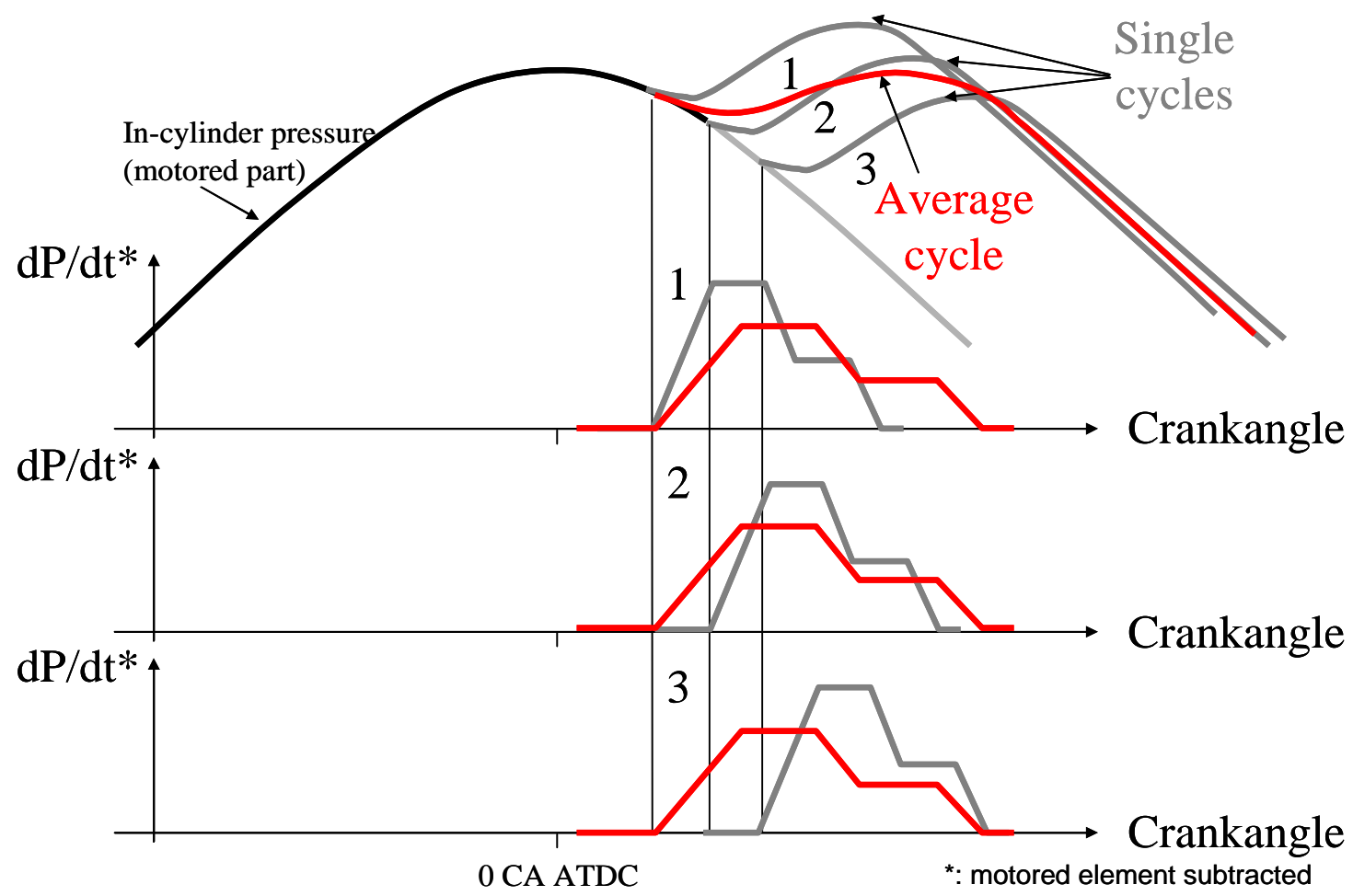

Figure 2

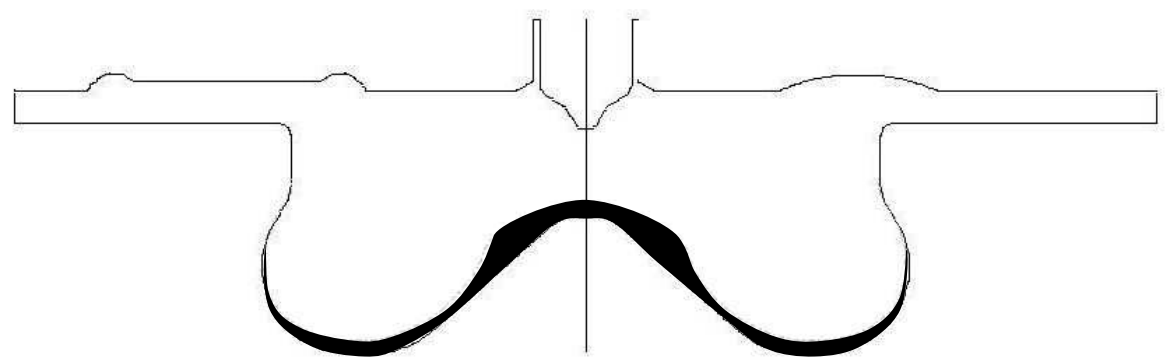


Figure 3

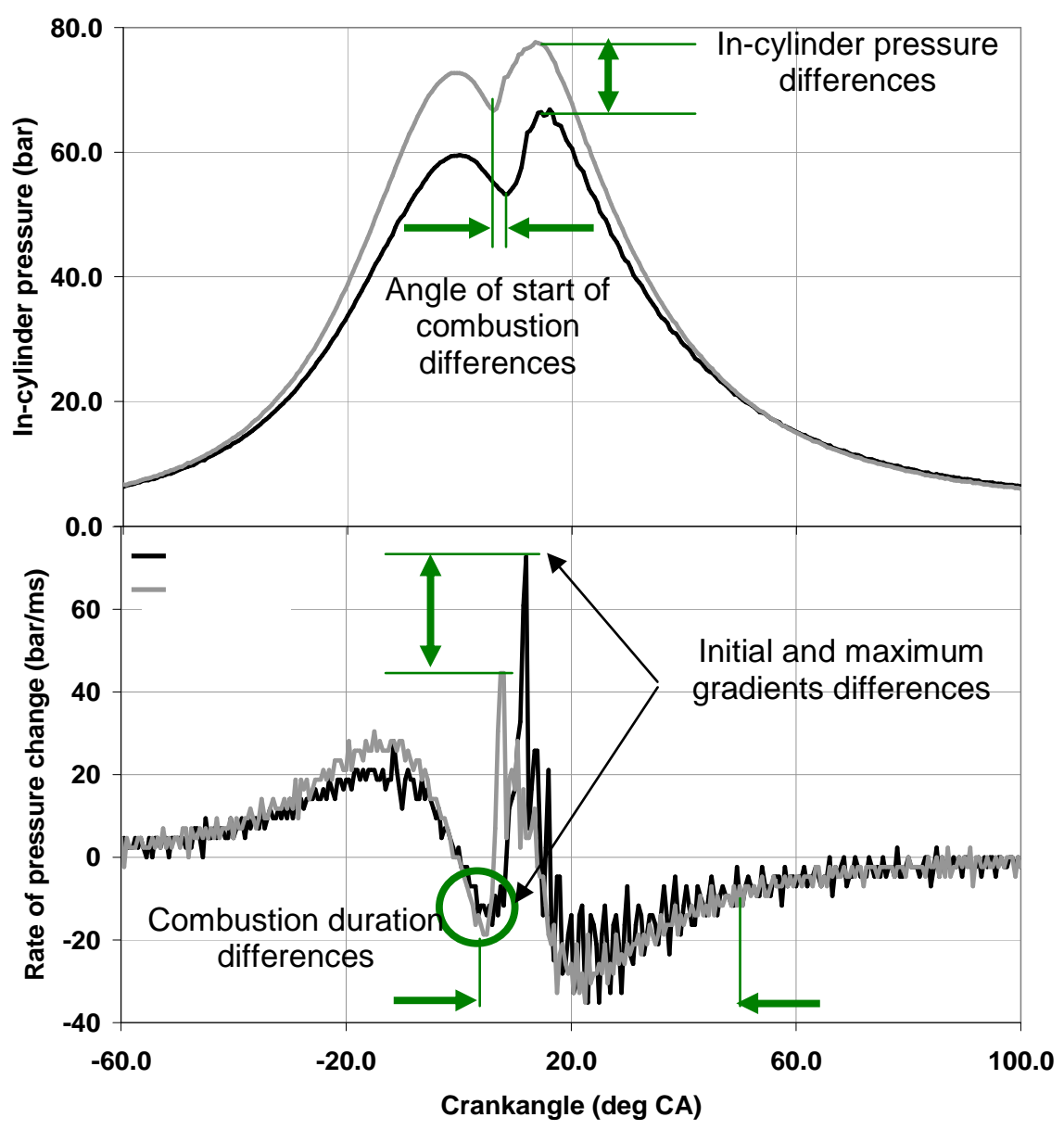


Figure 4

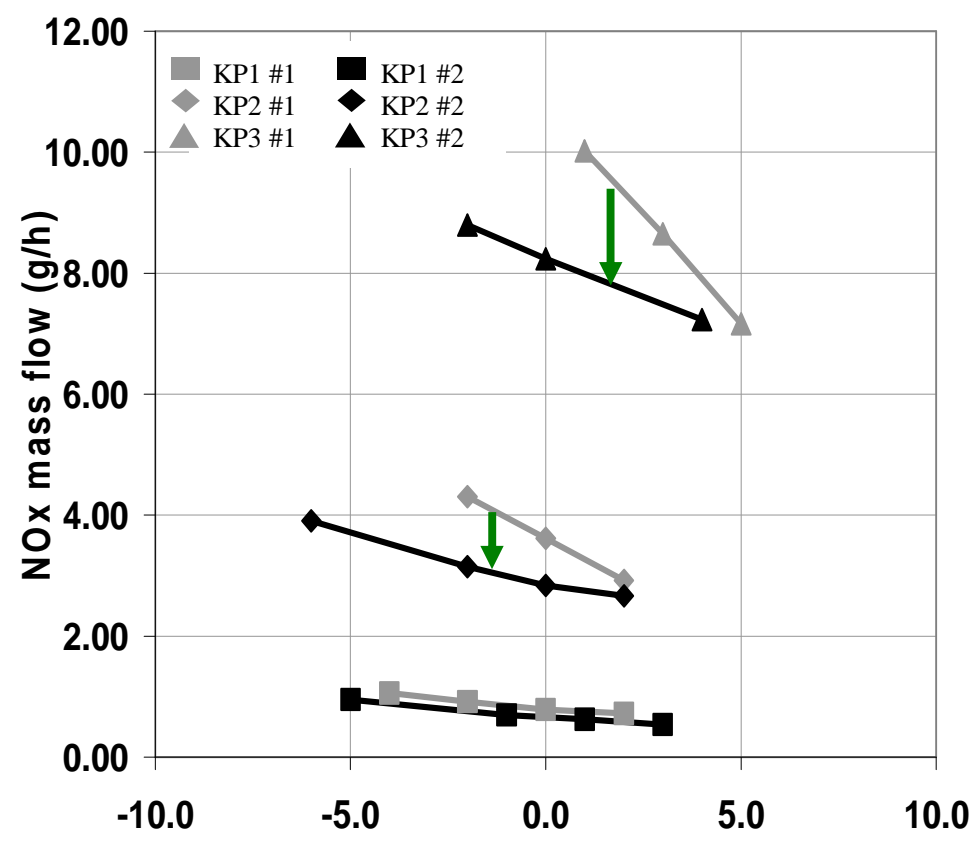

Angle of start of main injection (deg CA ATDC) 
Figure 5

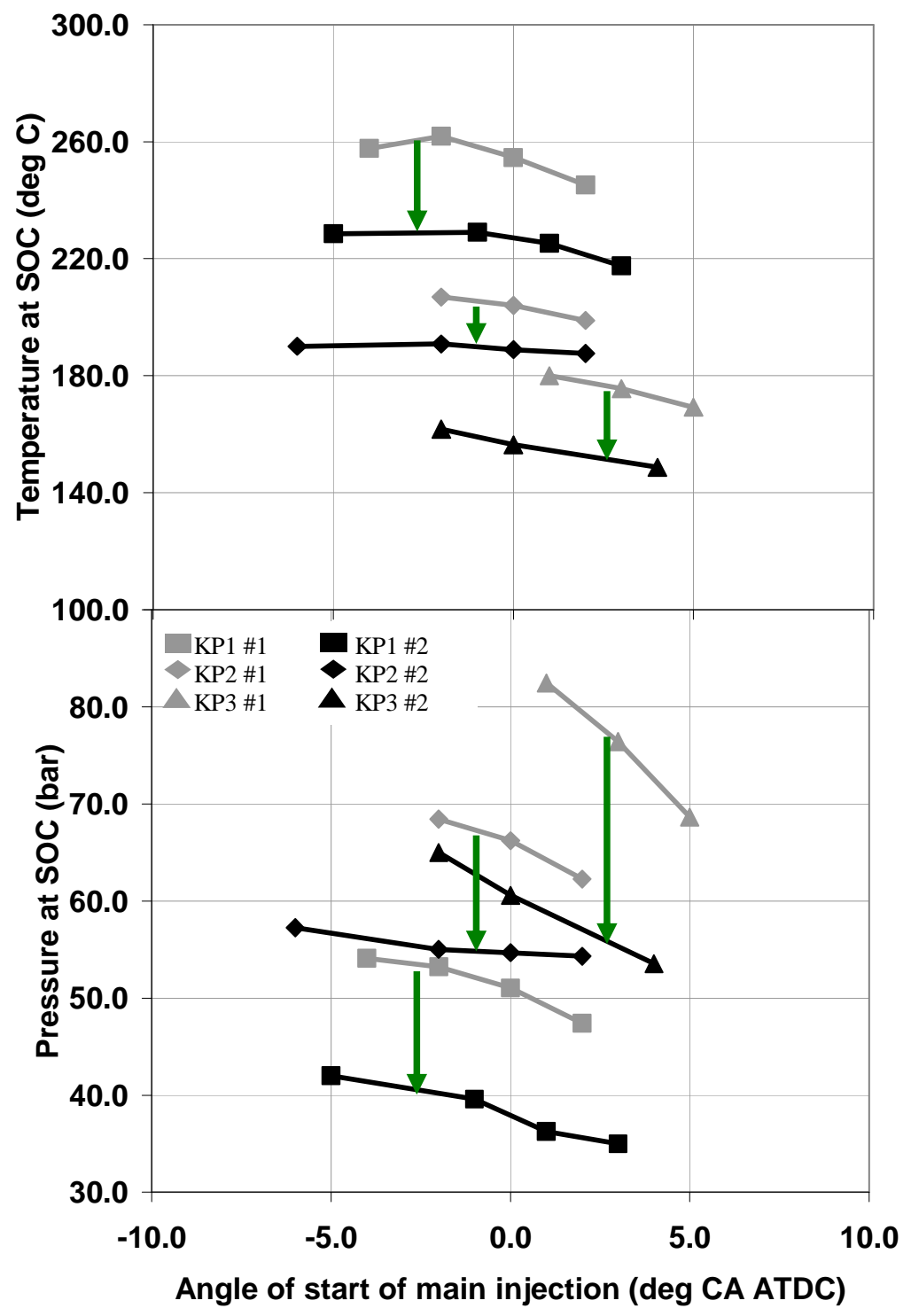


Figure 6

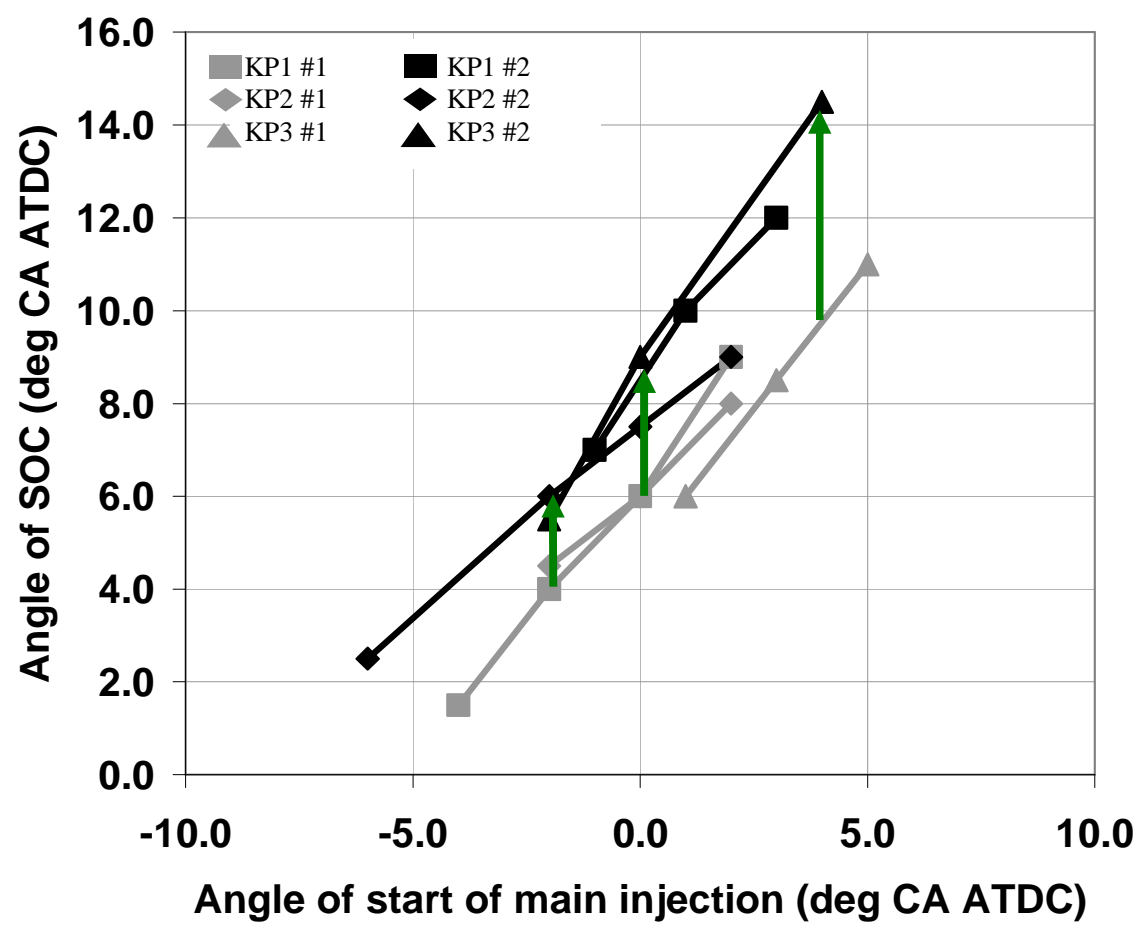

Figure 7

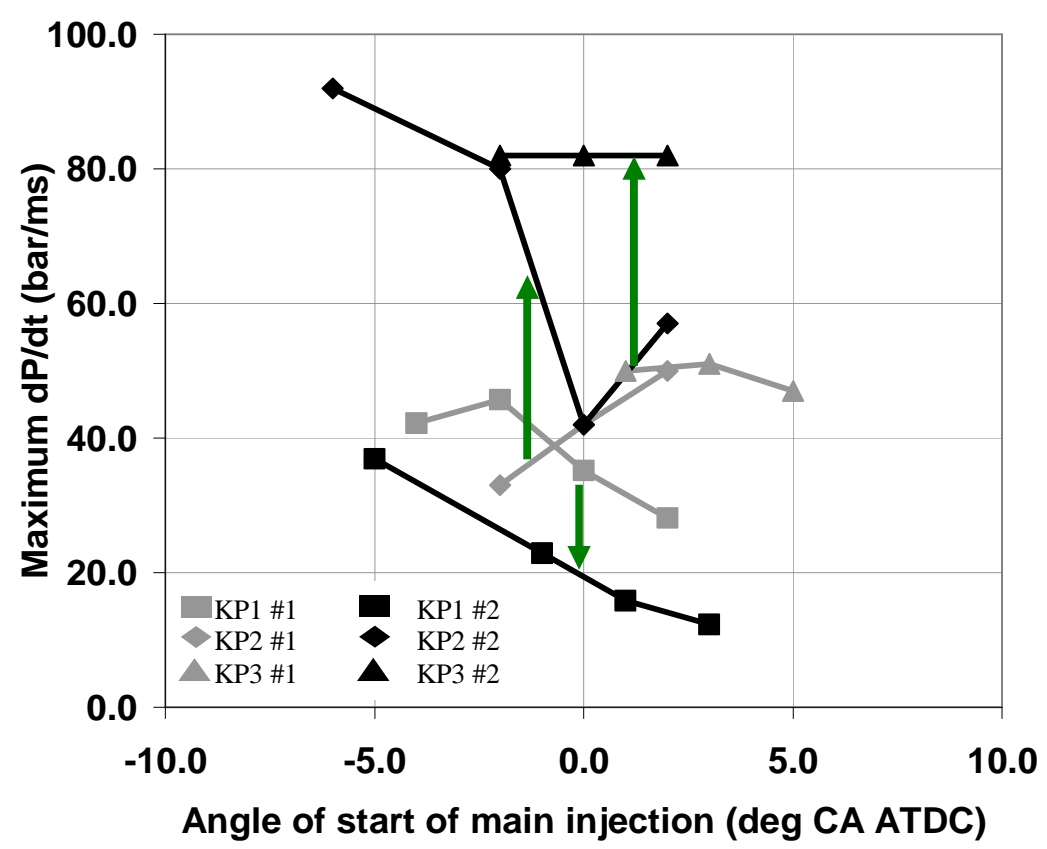


Figure 8

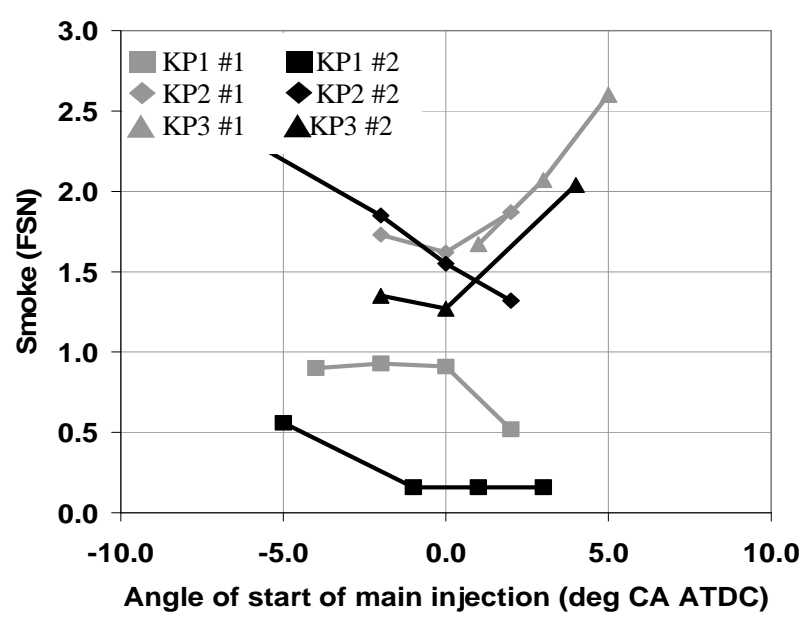

Figure 9

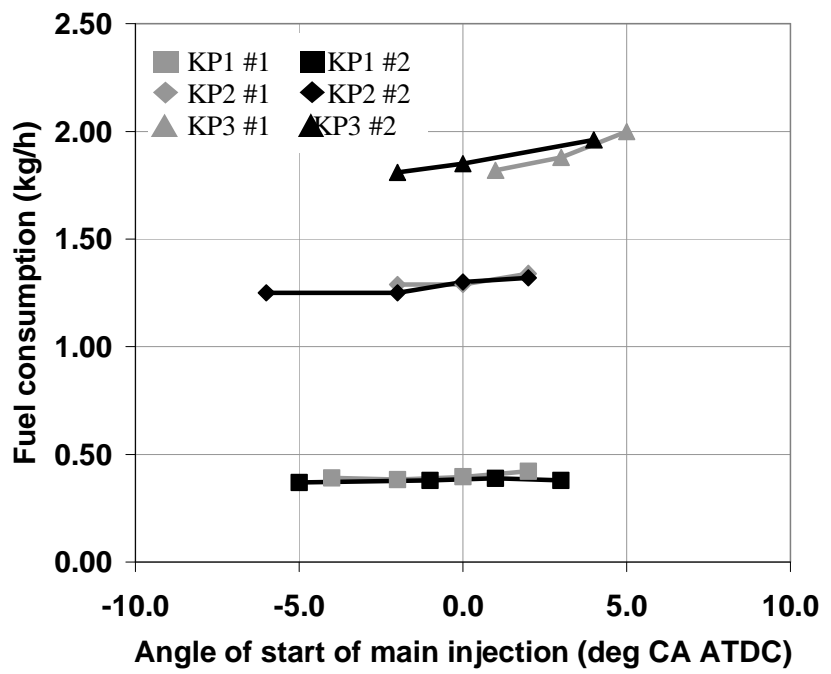




\section{Tables}

Table 1

\begin{tabular}{|c|c|c|c|}
\hline & Build \#1 & Build \#2 \\
\hline \multirow{3}{*}{ 导 } & $\begin{array}{l}\text { Swept volume } \\
\text { Bore } x \text { stroke } \\
\text { Inlet valves arrangement } \\
\text { Speed range } \\
\end{array}$ & \multicolumn{2}{|c|}{$\begin{array}{c}500 \mathrm{cc} \\
86 \mathrm{~mm} \times 86 \mathrm{~mm} \\
\text { One tangential and one helical valve } \\
750 \text { to } 4500 \mathrm{rev} / \mathrm{min}\end{array}$} \\
\hline & $\begin{array}{l}\text { Maximum in-cylinder pressure } \\
\text { Maximum exhaust temperature }\end{array}$ & \multicolumn{2}{|c|}{$\begin{array}{c}1000 \mathrm{rev} / \mathrm{min}: 11 \mathrm{MPa} \\
1250 \mathrm{rev} / \mathrm{min}: 13 \mathrm{MPa} \\
1500 \mathrm{rev} / \mathrm{min} \text { and higher: } 15 \mathrm{MPa} \\
760^{\circ} \mathrm{C}\end{array}$} \\
\hline & $\begin{array}{l}\text { Compression ratio } \\
\text { Piston bowl volume } \\
\text { Level of swirl range }\end{array}$ & $\begin{array}{c}18.4: 1 \\
22.0 \mathrm{cc} \\
1.5 \text { to } 4.5 \mathrm{Rs}\end{array}$ & $\begin{array}{c}16.0: 1 \\
26.3 \mathrm{cc} \\
1.0 \text { to } 3.5 \mathrm{Rs}\end{array}$ \\
\hline 들 & $\begin{array}{l}\text { Fuel type } \\
\text { High-pressure pump } \\
\text { Fuel pressure range } \\
\text { Injector } \\
\text { Injector nozzle }\end{array}$ & $\begin{array}{r}\text { Ultra low Sulph } \\
\text { De } \\
30 \\
\text { Delph } \\
\text { 7-hole, } 135 \mu \mathrm{m} \mathrm{h} \\
154^{\circ}, 0.76 \mathrm{cc}\end{array}$ & $\begin{array}{l}\text { (reference fuel) } \\
1.2 \\
\mathrm{~Pa} \\
\mathrm{Fl} 1.3 \\
\text { eter, } 680 \mathrm{cc} / \mathrm{min} \text {, } \\
\text { of discharge }\end{array}$ \\
\hline
\end{tabular}

Table 2

\begin{tabular}{|c|c|c|c|c|c|c|c|}
\hline & \multirow{3}{*}{\begin{tabular}{|l|} 
Key point \\
Build \\
\end{tabular}} & \multicolumn{6}{|c|}{ Values or ranges investigated } \\
\hline & & \multicolumn{2}{|c|}{ KP1 } & \multicolumn{2}{|c|}{ KP2 } & \multicolumn{2}{|c|}{ KP3 } \\
\hline & & $\# 1$ & $\# 2$ & $\# 1$ & \#2 & $\# 1$ & \#2 \\
\hline \multirow{3}{*}{ 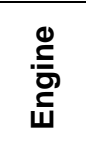 } & Speed (rev/min) & \multicolumn{2}{|c|}{1500} & \multicolumn{2}{|c|}{2000} & \multicolumn{2}{|c|}{2000} \\
\hline & Gross load (bar GIMEP) & \multicolumn{2}{|c|}{3.0} & & & & \\
\hline & $\begin{array}{l}\text { Compression ratio } \\
\text { Piston-bowl volume }\left(\mathrm{cm}^{3}\right)\end{array}$ & \multicolumn{6}{|c|}{$\begin{array}{c}\text { \#1: } 18.4: 1 \text { / \#2: 16.0:1 } \\
\text { \#1: } 22.0 \text { / \#2: } 26.3\end{array}$} \\
\hline \multirow{5}{*}{ 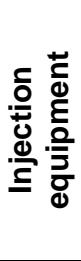 } & \multirow{5}{*}{$\begin{array}{l}\text { Injector nozzle } \\
\text { Main-injection quantity } \\
\text { Injection pressure (bar) } \\
\text { Pilot-injection duration ( } \mu \mathrm{s}) \\
\left.\text { Pilot separation ( }{ }^{\circ} \mathrm{CA}\right) \\
\text { SOI } 2 \text { ('CA ATDC) }\end{array}$} & \multicolumn{6}{|c|}{$\begin{array}{c}\text { 7-hole, } 680 \mathrm{cc} / \mathrm{min}, 154^{\circ}, 0.76 \text { coefficient } \\
\text { of discharge } \\
\text { Adjusted to maintain load }\end{array}$} \\
\hline & & \multicolumn{2}{|c|}{545} & \multicolumn{2}{|c|}{1070} & \multicolumn{2}{|c|}{1190} \\
\hline & & 300 & 350 & 210 & 250 & $\mathrm{n} / \mathrm{a}$ & $\mathrm{n} / \mathrm{a}$ \\
\hline & & 26.0 & 19.0 & 33.0 & 16.0 & $\mathrm{n} / \mathrm{a}$ & \\
\hline & & -5.0 & 3.0 & -6.0 & 2.0 & -1.0 & 3.0 \\
\hline \multirow{4}{*}{ 离 } & Wet EGR rate (\%) & \multicolumn{2}{|c|}{45.4} & \multicolumn{2}{|c|}{31.3} & \multicolumn{2}{|c|}{21.3} \\
\hline & Dry AFR (-) & \multicolumn{2}{|c|}{ 29.3:1 } & \multicolumn{2}{|c|}{$21.6: 1$} & \multicolumn{2}{|c|}{ 21.1:1 } \\
\hline & Swirl throttle (\% shut) & \multirow{2}{*}{\multicolumn{2}{|c|}{$\begin{array}{c}46 \\
88\end{array}$}} & \multirow{2}{*}{\multicolumn{2}{|c|}{$\begin{array}{l}64 \\
68\end{array}$}} & \multirow{2}{*}{\multicolumn{2}{|c|}{$\begin{array}{r}0 \\
58\end{array}$}} \\
\hline & Inlet temperature $\left({ }^{\circ} \mathrm{C}\right)$ & & & & & & \\
\hline
\end{tabular}

